J Neurosurg 119:1323-1330, 2013

(C)AANS, 2013

\title{
The impact of smoking on neurosurgical outcomes
}

\author{
A review \\ Darryl Lau, M.D., ${ }^{1}$ Mitchel S. Berger, M.D., ${ }^{1}$ Dhruv Khullar, B.A., ${ }^{2}$ \\ AND JoHN MAA, M.D. ${ }^{3}$ \\ ${ }^{1}$ Department of Neurological Surgery and ${ }^{3}$ Division of General Surgery, University of California, \\ San Francisco, California; and ${ }^{2}$ Yale University School of Medicine, New Haven, Connecticut
}

\begin{abstract}
Cigarette smoking is a common health risk behavior among the general adult population, and is the leading preventable cause of morbidity and mortality in the US. The surgical literature shows that active tobacco smoking is a major risk factor for perioperative morbidity and complications, and that preoperative smoking cessation is an effective measure to lower these risks associated with active smoking. However, few studies have examined the effects of smoking and perioperative complications following neurosurgical procedures. The goal of this review was to highlight the scientific data that do exist regarding the impact of smoking on neurosurgical outcomes, to promote awareness of the need for further work in the specific neurosurgical context, and to suggest ways that neurosurgeons can promote smoking cessation in their patients and lead efforts nationally to emphasize the importance of preoperative smoking cessation. This review indicates that there is limited but good evidence that smoking is associated with higher rates of perioperative complications following neurosurgical intervention. Specific research is needed to understand the effects of smoking and perioperative complications. Neurosurgeons should encourage preoperative smoking cessation as part of their clinical practice to mitigate perioperative morbidity associated with active smoking.
\end{abstract}

(http://thejns.org/doi/abs/10.3171/2013.5.JNS122287)

\section{$\begin{array}{lccccc}\text { KEY WORDS } & \text { complication } & \bullet & \text { morbidity } & \bullet & \text { neurosurgery } \\ \text { cigarette smoking } & \bullet & \text { tobacco }\end{array}$}

$\mathrm{C}$ IGARETTE smoking is the leading preventable cause of morbidity and mortality in the US. Even at low levels, tobacco smoke has been shown to be detrimental to overall health, ${ }^{9}$ and is associated with cancer, coronary artery disease, chronic obstructive pulmonary disease, cerebrovascular disease, peripheral vascular disease, and birth defects. ${ }^{1,26,44,47,85}$ One in 5 deaths in the US is attributed to tobacco use, which translates to nearly half a million deaths annually ${ }^{86}$ In addition, the tobaccorelated burden of morbidity and mortality is a significant strain on medical expenditures and health care systems. ${ }^{12}$ Despite the push for tobacco cessation and the advances in tobacco control, an estimated 44 million Americans continue to smoke and the prevalence continues to rise, making this an ever more important issue..$^{73,86}$

Abbreviation used in this paper: $\mathrm{SAH}=$ subarachnoid hemorrhage.
Smoking has long been identified as a risk factor for chronic disease, but expanding evidence in the surgical literature demonstrates that tobacco smoking is also a risk factor for perioperative morbidity and complications. ${ }^{42,93,97}$ Active smoking has been clearly linked to increased risk of perioperative cardiovascular complications, pulmonary complications, and wound healing complications (including infections, anastomotic dehiscence, reintubation, and respiratory failure). ${ }^{42}$ These complications in turn result in longer hospital stays, higher rates of ICU admission, greater need for repeat surgery, and higher overall costs of care. ${ }^{42}$ The impact of smoking on perioperative outcomes is relatively well defined in general surgery, ${ }^{96}$ cardiac surgery, ${ }^{23,35,97}$ plastic surgery, ${ }^{50,78,79,84,105}$ orthopedic surgery, ${ }^{6,72,83,89}$ and pediatric surgery. ${ }^{25,60,70,88}$

Among the neurosurgical subspecialties, it is generally well accepted that smoking leads to increased risk for intracranial aneurysm formation, ${ }^{17,28,32,36,39,75,77}$ aneurysmal 
SAH, ${ }^{8,36-38,57,76}$ and decreased bone healing and fusion after spine surgery. ${ }^{21,34,61}$ However, the effects of smoking on perioperative morbidity following neurosurgical procedures are less well defined. In this review, we sought to highlight the existing scientific data regarding the impact of smoking on neurosurgical outcomes, identify where additional studies are needed, and suggest ways that neurosurgeons can lead the efforts nationally to emphasize the importance of preoperative smoking cessation.

\section{Methods}

The words "smoking and neurosurgery" or "tobacco and neurosurgery" were used as search terms in PubMed (for the years 1950-2012) to identify all articles that included at least one of these terms or phrases. The references lists of the relevant articles and systematic reviews were scanned for additional sources.

\section{Results}

\section{How Smoking Increases Perioperative Complications}

Cigarette smoking is associated with numerous toxic effects to the body, even at the cellular level: cellular damage secondary to free radical release, ${ }^{33}$ tissue hypoxia, ${ }^{14}$ compromised immune cell function, ${ }^{107}$ and microvascular injury leading to dysfunction and thrombogenesis. ${ }^{50}$ Each of these mechanisms can contribute to the multitude of smoking-related complications seen in the perioperative period. The increased perioperative morbidity risk that smoking poses for patients is probably related to both the acute and long-term consequences of tobacco use.

Cellular Injury and Vascular Dysfunction. One of the best-understood mechanisms of the way that smoking can lead to perioperative complications relates to the pathophysiological effects of smoking that cause tissue hypoxia, thrombogenesis, and vasoconstriction. Tissue hypoxia is thought to be secondary to direct damage of the microvasculature that results in detachment of endothelial cells from the lumen of small vessels. The loss of endothelial protection results in exposure of a prothrombogenic/procoagulant basement membrane, increased platelet activation, and activation of the coagulation cascade. ${ }^{50}$ In addition, as endothelial cells are injured and detached from the microvasculature, there is an intrinsic deficiency in endothelial-derived relaxing factor, which leads to a decrease in anticoagulation and antispasmodic factors. ${ }^{50}$ The end result of this process is hypercoagulability and vasoconstriction, and both mechanisms can lead to cellular and tissue hypoxia.

Tissue hypoxia is further exacerbated by the systemic effects of nicotine and carbon monoxide. Residual nicotine in the blood can activate the sympathetic nervous system, induce release of epinephrine and norepinephrine from the adrenal glands, ${ }^{98}$ and increase leukotriene and thromboxane levels., ${ }^{2,15}$ The increase of these metabolites leads to additional vasoconstriction of microvasculature. ${ }^{14,46}$ Carbon monoxide is found in high concentrations as a toxic byproduct of tobacco smoke. Its pathophysiological mechanism involves the competitive binding of hemoglobin and consequent decrease in the oxygen-carrying capacity of blood. A chronic hypoxic state (due to binding of carbon monoxide to hemoglobin) can stimulate a physiological erythropoietic response as a compensatory mechanism. Increased blood cell count and mass can lead to the consequences of red cell aggregation, increased blood viscosity, and thrombogenicity. ${ }^{79}$

These cumulative effects of tobacco smoking effectively result in the Virchow triad for thrombosis as well: endovascular injury/dysfunction, hemostasis (increased viscosity), and stasis (especially for procedures with associated postoperative immobility). ${ }^{27}$

Wound Healing and Infection. Wound healing is highly dependent on the ability of the vasculature to provide essential nutrients, oxygen, growth factors, and immune cells. Therefore dysfunction of the microvasculature can lead to significantly impaired wound healing. ${ }^{107}$ Tobacco smoking results in significant injury and dysfunction of the vasculature, and therefore may cause decreased oxygen, nutrients, and immune cells at the site of incision, which are essential for wound healing. ${ }^{65} \mathrm{In}$ addition, tobacco may stimulate a stress response mediated by enhanced fibroblast activity, resulting in decreased cell migration and increased cell adhesion. The net consequence is inappropriate connective tissue deposition at the surgical site, delayed wound healing, and increased risks of wound infection. . $^{53,107}$

Intraoperative Blood Loss. In the neurosurgical literature, 2 retrospective clinical studies suggest that active smokers tend to have higher intraoperative blood loss following craniotomy for tumor resection and lumbar spine surgery. ${ }^{20,53}$ The exact underlying mechanism has yet to be defined. In the literature regarding craniotomy for tumor resection, there is evidence that cigarette smoking can lead to an acute hyperemia response and longterm morphological changes within the cerebral vasculature. ${ }^{2,22,95}$ Acute hyperemia is a result of a buildup of transient vasodilating metabolites in blood vessel $\mathrm{s}^{2,95}$ and causes increased blood flow within the cerebral vasculature, which can potentially contribute to an increase in blood loss during craniotomy. With regard to long-term plastic changes, smoking causes permanent structural changes of vessels such as vessel wall thickening, which can result in the dysfunction and/or inhibition of vessel accommodation during bleeding. ${ }^{45}$ These correlate with a Doppler ultrasonography study that showed impairment of the cerebral vasculature even after smoking cessation. ${ }^{11}$ In addition, tumor vascularity probably plays a role in blood loss intraoperatively. There is evidence that cigarette smoking is associated with increased proliferation and angiogenesis of blood vessels, leading to larger and more vascularized tumors, which may further contribute to intraoperative blood loss during resection. ${ }^{62,109}$

Cardiopulmonary Effects. Although pulmonary complications can result from poor lung function and/or exacerbation of chronic smoking-related diseases, even smokers without chronic disease are at increased risk for perioperative morbidity. ${ }^{101}$ There are many mechanisms for which tobacco smoking increases the risk for pulmonary com- 
plications in the perioperative period. Oxidative damage following smoke exposure can result in mucosal damage, goblet cell hyperplasia, ciliary dysfunction, and impaired bronchial function, which leads to the inability to expel mucus. ${ }^{4,82}$ This can further translate the respiratory environment into a favorable nidus for pathogenic organisms and lead to infection and possibly respiratory failure. In fact, smokers tend to have delayed bacterial clearance and increased bacterial load compared with their nonsmoking counterparts. ${ }^{24}$ In addition, smoking alters the respiratory immune response: it leads to increased airway inflammation resulting in bronchial hyperreactivity, ${ }^{30}$ and impaired alveolar macrophage function, further contributing to higher rates of postoperative pneumonia. ${ }^{56}$

As with pulmonary complications, the adverse perioperative cardiovascular effects of smoking are thought to have both chronic and acute contributions. Long-term tobacco smoking promotes systemic atherosclerosis, alteration of lipid metabolism via increased lipolysis and lipotoxicity, and insulin resistance. ${ }^{31}$ The most devastating sequelae from these systemic abnormalities are macrovascular complications such as perioperative myocardial infarct, pulmonary embolus, and even stroke. But even short-term smoking exposure poses a significant perioperative morbidity risk through mechanisms of increased coagulability, increased sympathetic tone, and reduced oxygen-carrying capacity. ${ }^{101}$ In smokers the reduced oxygen-carrying capacity is an additional risk factor for decreased oxygen supply to the heart, which places these patients at even higher risk for myocardial ischemia and/ or infarct.

\section{The Evidence: Smoking and the Risks in Neurosurgery}

Cranial Surgery. Only a few studies have examined how smoking affects perioperative morbidity and mortality following neurosurgical intervention (Table 1). The most robust studies of tobacco smoking and its association with morbidity in neurosurgery are in the cerebrovascular literature. Abundant evidence demonstrates that smoking is highly associated with the risk for aneurysm formation ${ }^{17,28,32,36,39,75,77}$ and aneurysm rupture/SAH. ${ }^{8,36-38}$, ${ }^{57,76}$ In fact, smoking cessation has been suggested as an excellent alternate treatment for older patients with small intracranial aneurysms..$^{38}$

Several studies examining smoking and the treatment of cerebrovascular disorders provide good evidence that smoking is associated with greater perioperative morbidity and worse outcomes. A retrospective study of 320 patients with aneurysmal SAH who underwent surgical or endovascular treatment showed that current smokers (patients with at least a 10 pack-year history and who were still smoking during the past year) and patients with a 20 pack-year or longer history of tobacco use were more likely to experience neurological deterioration occurring at least 2 days after intervention. ${ }^{48}$ Other studies of postoperative outcomes of aneurysmal SAH have also shown that smokers have higher rates of pulmonary complications,${ }^{66}$ greater need for ventilation ${ }^{66}$ and greater risk for cerebral vasospasm. ${ }^{74,106}$ Smokers even have higher rates of complications following diagnostic cerebral angiography and neuroendovascular procedures. ${ }^{54}$ Altered wound healing has also been seen after superficial temporal artery-middle cerebral artery anastomosis; more specifically, it has been suggested that smokers have higher rates of cutaneous necrosis. ${ }^{41}$

Within the subspecialty of neurooncology, just one study has evaluated the association between tobacco smoking and perioperative outcome after craniotomy for tumors. It was a retrospective study of 453 patients in which it was found that current smoking status was an independent risk factor for higher intraoperative blood loss, postoperative complication risk, and lower 1-year survival following craniotomy for tumor resection. ${ }^{53}$ Another finding was that patients who quit smoking continued to have significantly higher mean blood loss, but did not carry a higher risk for postoperative complications and 1-year mortality. This may demonstrate that smoking cessation may be effective in mitigating the perioperative morbidity risks associated with active smoking after tumor resection.

Two studies examined the effects of smoking on specific cranial procedures. A single-center retrospective study of 475 patients found that smoking does not seem to affect the risk of infection and CSF leakage after the use of collagen sponge dural allografts. ${ }^{59}$ Similarly, smoking was not a risk factor for failure in tissue cranial reconstruction. ${ }^{69}$ The last study, however, was a retrospective review of only 21 patients.

Spine Surgery. The neurosurgical spine literature contains considerable evidence that smoking is associated with worse long-term outcomes, but there are few studies of smoking and its effects on perioperative morbidity and mortality. Most of the data pertaining to spine surgery demonstrates that smoking is associated with de-

TABLE 1: Studies evaluating the effect of smoking on neurosurgical procedures

\begin{tabular}{|c|c|c|c|}
\hline Authors \& Year & Procedure Type & $\begin{array}{l}\text { No. of } \\
\text { Patients }\end{array}$ & Results \\
\hline Lau et al., 2012 & craniotomy for tumor resection & 453 & $\begin{array}{l}\text { smokers had higher rates of blood loss \& complications; smokers } \\
\text { who quit had reduced risk of postop complications \& higher 1-yr } \\
\text { survival rates compared to active smokers }\end{array}$ \\
\hline Litvack et al., 2009 & $\begin{array}{l}\text { collagen sponge dural graft implant following } \\
\text { craniotomy }\end{array}$ & 475 & smoking did not affect risk of infection or CSF leak \\
\hline $\begin{array}{l}\text { Krishnamurthy et al., } \\
2007\end{array}$ & clip \&/or coil occlusion of aneurysmal SAH & 320 & smokers more likely to experience delayed neurological deterioration \\
\hline Dean et al., 2006 & lumbar spine surgery & 500 & smoking associated w/ increased blood loss \& intraop transfusion \\
\hline
\end{tabular}


layed spinal fusion, ${ }^{55}$ poor spinal fusion rates, ${ }^{21,34,61}$ and higher rates of pseudarthrosis following spinal instrumentation. ${ }^{108}$ Smoking has been identified as a risk factor for higher subsidence rates in the placement of carbon fiber cages following anterior cervical discectomy and fusion. ${ }^{7}$ The mechanism behind poor fusion and greater rates of subsidence in smokers is related to poor bone quality secondary to tobacco smoking. Nicotine exposure is associated with delayed vascularization and smaller areas of revascularization, which lead to reduced levels of osteogenesis and hypocellular fusion mass. ${ }^{19}$ There is also evidence that smokers have higher rates of recurrent lumbar disc herniation after surgery. ${ }^{16,43,92}$ The higher rates of recurrent disc herniation are possibly secondary to nicotine-induced vasoconstriction and decreased blood flow to the area of prior surgery. ${ }^{43}$ This results in the inhibition of the annular healing process and degeneration.

The only study that directly evaluated whether tobacco smoking affected perioperative outcomes was a retrospective review of 500 patients that demonstrated that smoking was associated with increased surgical blood loss and intraoperative transfusion following lumbar spine surgery. ${ }^{20}$

Peripheral Nerve Surgery. The neurosurgical literature contains no studies that directly examined the effects of smoking and perioperative outcomes after surgery for diseases of the peripheral nervous system.

\section{Applicability of Studies From Other Surgical Specialties}

Of the surgical literature on the association of smoking and perioperative complications, the most applicable to neurosurgery comes from the specialties of plastic surgery, orthopedic surgery, and vascular surgery. In plastic surgery, wound healing is of paramount importance because success is often judged largely on aesthetic appearance. Plastic surgery studies have shown that tobacco smokers have increased rates of wound infections, reduced skin flap survival, and increased risk for skin necrosis. ${ }^{5,13,49,50}$ Similar to procedures in plastic surgery, neurosurgical procedures often involve large incisions in readily visible areas, as are used when performing a craniotomy. Therefore, proper and optimal wound healing is important because this may have large implications for appearance and quality of life, especially in the pediatric population.

Because orthopedic surgery is often involved with the surgical management of the spine, studies from this discipline are clearly applicable to neurosurgical patients who are undergoing spine surgery. Two orthopedic studies have demonstrated that tobacco smoking is associated with poor fusion rates, supporting similar findings in the neurosurgical literature. ${ }^{87,108}$ In a retrospective study of 4555 patients, smoking cessation was associated with less residual back pain and less need for analgesic drugs. ${ }^{83}$

Carotid endarterectomy is performed both by general vascular surgeons and by neurosurgeons; therefore, findings from the vascular literature regarding smoking's effect on perioperative outcomes after endarterectomy are most likely to be applicable to neurosurgery as well. Among patients who experience perioperative stroke as a complication following endarterectomy, a significant portion are active smokers, and therefore it is suggested that active smoking status is a risk factor for perioperative stroke following this procedure. ${ }^{81}$ In addition, a randomized controlled trial showed that active smoking status is a risk factor for restenosis following carotid endarterectomy. ${ }^{52}$

\section{Discussion}

Our review of tobacco smoking and perioperative outcomes in neurosurgery indicates that the limited literature available provides evidence that smoking is associated with higher perioperative morbidity after neurosurgical intervention (Table 2). Most of the studies were done in the subspecialties of cerebrovascular surgery and spine surgery. Compared with studies from other surgical specialties, few in neurosurgery concentrate on the effects of smoking on perioperative rather than longterm outcomes. Although it may be appropriate to apply certain findings from other fields such as plastic surgery, orthopedics, and vascular surgery for the time being, further studies are needed to assess the effects of smoking and perioperative complications following specific neurosurgical procedures. Nevertheless, tobacco smoking is an overall detriment to patient health, and smoking cessation should be encouraged preoperatively to mitigate the associated risk for complications and to reap the long-term benefits of neurosurgical treatment.

\section{Evidence of the Effect of Smoking Cessation on Surgical Outcomes}

Accumulating evidence indicates that smoking cessation can reduce the higher perioperative complications risk seen in active smokers and possibly improve longterm outcomes. A randomized clinical trial demonstrated that a 4-week smoking cessation program consisting of individual counseling and nicotine replacement provided a $49 \%$ relative risk reduction in postoperative complications among smokers. ${ }^{58}$ Another clinical trial showed a significant decrease in complication rates, especially wound healing, when patients abstained from smoking for 6-8 weeks. ${ }^{64} \mathrm{~A}$ third trial demonstrated a significant decrease in postoperative complications after repair of acute fractures ${ }^{68}$ However, one randomized trial was an exception; it showed that 2 -week preoperative smoking cessation did not change postoperative complication rates and risk following colorectal surgery ${ }^{91}$ However, a major drawback to this study was that it was originally powered to 0.80 if 300 patients were included, but only 60 patients were included in the final analysis. This dramatically limits the ability to detect a potential benefit.

Because there is strong evidence from the other randomized clinical trials that smoking cessation is effective in decreasing perioperative morbidity risk, preoperative smoking cessation should be implemented to improve neurosurgical outcomes. The exact duration of abstinence required for these benefits to be observed is unclear. ${ }^{102,103}$ The benefit probably depends both on the duration of cessation and the neurosurgical complication of interest. The suggested durations of smoking cessation range from hours to days for cardiovascular complications, ${ }^{40,99}$ and even months for pulmonary complications, depend- 
Impact of smoking in neurosurgery

TABLE 2: Major smoking-related morbidities by neurosurgical subspecialty

\begin{tabular}{lll}
\hline \multicolumn{1}{c}{ Subspecialty } & \multicolumn{1}{c}{ Perioperative Morbidity } & \multicolumn{1}{c}{ Long-Term Complications } \\
\hline neurooncology & intraop blood loss, postop complications & lower 1-yr survival \\
spine surgery & intraop blood loss, increased need for transfusion & $\begin{array}{c}\text { delayed spine fusion, pseudarthrosis, higher subsidence rates, recurrent } \\
\text { lumbar disc herniation }\end{array}$ \\
cerebrovascular & $\begin{array}{c}\text { neurological deterioration, stroke, altered wound healing/ } \\
\text { cutaneous necrosis, pulmonary complications }\end{array}$ & \begin{tabular}{l} 
aneurysture, aneurysm formation \\
\hline
\end{tabular} \\
\hline
\end{tabular}

ing on the study. ${ }^{100}$ Most trials have found that 4-8 weeks of smoking abstinence significantly reduces perioperative complications and the need for repeat surgery. ${ }^{58,63,64}$ There are even trials that demonstrate that just 3 weeks of smoking cessation is beneficial. ${ }^{71}$

Although it may seem intuitive that smoking cessation should be encouraged whenever possible and even for brief periods, there has been controversy in the past that brief preoperative abstinence may actually increase the risk of pulmonary complications, and that cessation must occur at least 8 weeks before surgery. ${ }^{10,51}$ However, a meta-analysis demonstrated no suggestion of increased postoperative complications associated with brief durations of smoking cessation. ${ }^{67}$ In addition, there is no reliable evidence that abstinence of any duration increases the risk for complications. ${ }^{90,93}$ Therefore, neurosurgeons can confidently and safely encourage preoperative smoking cessation at any time before surgery.

\section{Smoking Cessation: the "Teachable Moment" and Current Barriers}

Encouraging patients to quit smoking may seem quite simple, but in actuality and in clinical practice this is not the case, because tobacco is highly addicting. In addition, undergoing surgery is very stressful for many patients and, stress being a common motivator for smoking, may make quitting even more difficult. ${ }^{18}$ However, the seriousness of surgery can be used to the advantage of the clinician in motivating patients to quit smoking successfully. This relates to the phenomenon of a "teachable moment," in which an event such as disease diagnosis, hospitalization, or pregnancy motivates a patient to change a risky health behavior. During these times, patients may be more amenable to changing their habits and/or addiction because of the risk to self. In fact, it has been shown that patients tend to be more likely to quit smoking after hospitalization for serious illness. ${ }^{29,80}$ Therefore, not only does preoperative smoking cessation decrease perioperative morbidity, but scheduling surgery is a great opportunity to encourage permanent smoking cessation so the patient can reap the lifelong benefits of a tobacco-free life.

Despite the potential "teachable moment" that surgery presents for smoking cessation, neurosurgeons are currently not capitalizing on this event. Studies suggest that almost half of all surgeons do not routinely counsel their patients to stop smoking before an operation, and it is most likely that neurosurgeons are not an exception in this regard. ${ }^{104}$ In addition, smoking cessation counseling is practice dependent, and no set structures have been implemented to promote preoperative smoking cessation in the traditional neurosurgical practice. Brief counseling (less than 3 minutes) may increase rates of smoking cessation. ${ }^{40,64}$ However, even with appropriate counseling the failure rate of smoking cessation can remain high, and often multiple attempts are required. ${ }^{3}$ Therefore, methods need to be implemented to make sure patients remain successful in quitting their smoking habit. In one randomized trial of a perioperative smoking cessation intervention, high cessation rates were obtained-most likely because the intervention was intense and included repeated personal contact. ${ }^{58}$ More intensive smoking cessation programs are associated with higher quit rates and are effective in surgical settings, whereas other briefer and less intensive programs are less effective. ${ }^{94}$ Therefore, a strict smoking cessation program is likely to be the key to success for patients to stop smoking. Effective interventions that health care providers can use to help patients stop smoking include simple open dialog about the patient's motivation to quit smoking, individual counseling, group counseling, and repeated personal contact.

\section{Policy Implications}

There is considerable evidence that smoking is a major risk factor for perioperative complications, which points to a great opportunity to change policy and federal mandates regarding tobacco companies and the health care system. In 2009, landmark legislation that granted the FDA the authority to regulate tobacco was passed. However, in August of 2012, a US appeals court in Washington, DC, ruled that a requirement for graphic warning labels on cigarette boxes was unconstitutional and violated the First Amendment. The federal government subsequently asked for a further appeal of this ruling, but the US continues to lag behind other nations, which have implemented enhanced health warnings on cigarette packs. Therefore, alternative actions may be required to reduce smoking exposure: limits on the annual production of cigarettes by tobacco companies, an increase of taxes on the ingredients used to manufacture cigarettes, and restrictions on the height to which tobacco plants are allowed to grow. ${ }^{42}$ At a federal level, the creation of new policies that affect practicing neurosurgeons and medical care providers through the development and implementation of pay for performance mandates may be an effective incentive to further encourage patients to quit smoking preoperatively.

\section{Conclusions}

The surgical literature shows that active tobacco 
smoking is a major risk factor for perioperative morbidity and complications, and that preoperative smoking cessation is effective at lowering the risks associated with active smoking. The relatively few studies specifically in the neurosurgical literature do provide evidence that smoking is associated with higher rates of perioperative complications. Because one of the most powerful times to convince a smoker to quit is before a surgical procedure, neurosurgeons are encouraged to do so. On the policy level, neurosurgeons should take the lead in catalyzing constructive changes to minimize the impact of tobacco smoking in the perioperative setting.

\section{Disclosure}

Dr. Maa is vice chair of the University of California, Office of the President, Tobacco Related Disease Research Program's Scientific Advisory Committee. This is an unpaid position. The authors report no conflict of interest concerning the materials or methods used in this study or the findings specified in this paper.

Author contributions to the study and manuscript preparation include the following. Conception and design: Maa, Berger. Acquisition of data: all authors. Analysis and interpretation of data: all authors. Drafting the article: Maa, Lau. Critically revising the article: all authors. Reviewed submitted version of manuscript: Maa, Lau. Approved the final version of the manuscript on behalf of all authors: Maa. Study supervision: Maa.

\section{References}

1. Agudo A, Bonet C, Travier N, González CA, Vineis P, Buenode-Mesquita HB, et al: Impact of cigarette smoking on cancer risk in the European Prospective Investigation Into Cancer and Nutrition Study. J Clin Oncol 30:4550-4557, 2012

2. Altura BM: Role of prostaglandins and histamine in reactive hyperemia: in-vivo studies on single mesenteric arterioles. Prostaglandins Med 1:323-331, 1978

3. Anderson RC, Anderson KE: Success and failure attributions in smoking cessation among men and women. AAOHN J 38: $180-185,1990$

4. Auerbach O, Stout AP, Hammond EC, Garfinkel L: Changes in bronchial epithelium in relation to sex, age, residence, smoking and pneumonia. N Engl J Med 267:111-119, 1962

5. Bailey MH, Smith JW, Casas L, Johnson P, Serra E, de la Fuente R, et al: Immediate breast reconstruction: reducing the risks. Plast Reconstr Surg 83:845-851, 1989

6. Bannister G: Prevention of infection in joint replacement. Curr Orthop 16:426-433, 2002

7. Bartels RH, Donk RD, Feuth T: Subsidence of stand-alone cervical carbon fiber cages. Neurosurgery 58:502-508, 2006

8. Bhat AR, Afzalwani M, Kirmani AR: Subarachnoid hemorrhage in Kashmir: causes, risk factors, and outcome. Asian J Neurosurg 6:57-71, 2011

9. Bjartveit K, Tverdal A: Health consequences of smoking 1-4 cigarettes per day. Tob Control 14:315-320, 2005

10. Bluman LG, Mosca L, Newman N, Simon DG: Preoperative smoking habits and postoperative pulmonary complications. Chest 113:883-889, 1998

11. Boms N, Yonai Y, Molnar S, Rosengarten B, Bornstein NM, Csiba L, et al: Effect of smoking cessation on visually evoked cerebral blood flow response in healthy volunteers. J Vasc Res 47:214-220, 2010

12. Centers for Disease Control and Prevention: Smoking-attributable mortality, years of potential life lost, and productivity losses-United States, 2000-2004. MMWR Morb Mortal Wkly Rep 57:1226-1228, 2008

13. Chang DW, Reece GP, Wang B, Robb GL, Miller MJ, Evans GR, et al: Effect of smoking on complications in patients undergoing free TRAM flap breast reconstruction. Plast Reconstr Surg 105:2374-2380, 2000

14. Chang LD, Buncke G, Slezak S, Buncke HJ: Cigarette smoking, plastic surgery, and microsurgery. J Reconstr Microsurg 12:467-474, 1996

15. Chen G, Wang DX: Effects of cigarette smoking on hemodynamics and hypoxic pulmonary vasoconstriction: role of prostaglandins and leukotrienes. J Tongji Med Univ 9:222-227, 1989

16. Connolly ES: Surgery for recurrent lumbar disc herniation. Clin Neurosurg 39:211-216, 1992

17. Connolly ES Jr, Choudhri TF, Mack WJ, Mocco J, Spinks TJ, Slosberg J, et al: Influence of smoking, hypertension, and sex on the phenotypic expression of familial intracranial aneurysms in siblings. Neurosurgery 48:64-69, 2001

18. Cui X, Rockett IR, Yang T, Cao R: Work stress, life stress, and smoking among rural-urban migrant workers in China. BMC Public Health 12:979, 2012

19. Daftari TK, Whitesides TE Jr, Heller JG, Goodrich AC, McCarey BE, Hutton WC: Nicotine on the revascularization of bone graft. An experimental study in rabbits. Spine (Phila Pa 1976) 19:904-911, 1994

20. Dean C, Glenn W, Ahn U, Cassinelli E, Hart D, Bohlman H, et al: Smoking increases blood loss and transfusion requirements following lumbar spine surgery. Spine J 6 Suppl:26S27S, 2006

21. Dickman CA, Fessler RG, MacMillan M, Haid RW: Transpedicular screw-rod fixation of the lumbar spine: operative technique and outcome in 104 cases. J Neurosurg 77:860-870, 1992

22. Domino EF, Ni L, Xu Y, Koeppe RA, Guthrie S, Zubieta JK: Regional cerebral blood flow and plasma nicotine after smoking tobacco cigarettes. Prog Neuropsychopharmacol Biol Psychiatry 28:319-327, 2004

23. Dougenis DNS, Naik S, Brown AH: Is repeated coronary surgery for recurrent angina cost effective? Eur Heart J 13: 9-14, 1992

24. Drannik AG, Pouladi MA, Robbins CS, Goncharova SI, Kianpour S, Stämpfli MR: Impact of cigarette smoke on clearance and inflammation after Pseudomonas aeruginosa infection. Am J Respir Crit Care Med 170:1164-1171, 2004

25. Drongowski RA, Lee D, Reynolds PI, Malviya S, Harmon $\mathrm{CM}$, Geiger J, et al: Increased respiratory symptoms following surgery in children exposed to environmental tobacco smoke. Paediatr Anaesth 13:304-310, 2003

26. Erhardt L: Cigarette smoking: an undertreated risk factor for cardiovascular disease. Atherosclerosis 205:23-32, 2009

27. Esmon CT: Basic mechanisms and pathogenesis of venous thrombosis. Blood Rev 23:225-229, 2009

28. Etminan N, Beseoglu K, Steiger HJ, Hänggi D: The impact of hypertension and nicotine on the size of ruptured intracranial aneurysms. J Neurol Neurosurg Psychiatry 82:4-7, 2011

29. France EK, Glasgow RE, Marcus AC: Smoking cessation interventions among hospitalized patients: what have we learned? Prev Med 32:376-388, 2001

30. Garey KW, Neuhauser MM, Robbins RA, Danziger LH, Rubinstein I: Markers of inflammation in exhaled breath condensate of young healthy smokers. Chest 125:22-26, 2004

31. Gastaldelli A, Folli F, Maffei S: Impact of tobacco smoking on lipid metabolism, body weight and cardiometabolic risk. Curr Pharm Des 16:2526-2530, 2010

32. Gu YX, Chen XC, Song DL, Leng B, Zhao F: Risk factors for intracranial aneurysm in a Chinese ethnic population. Chin Med J (Engl) 119:1359-1364, 2006

33. Guo X, Wang WP, Ko JK, Cho CH: Involvement of neutrophils and free radicals in the potentiating effects of passive cigarette smoking on inflammatory bowel disease in rats. Gastroenterology 117:884-892, 1999

34. Hadley MN, Reddy SV: Smoking and the human vertebral 
column: a review of the impact of cigarette use on vertebral bone metabolism and spinal fusion. Neurosurgery 41:116124, 1997

35. Hasdai D, Garratt KN, Grill DE, Lerman A, Holmes DR Jr: Effect of smoking status on the long-term outcome after successful percutaneous coronary revascularization. N Engl J Med 336:755-761, 1997

36. Inagawa T: Risk factors for the formation and rupture of intracranial saccular aneurysms in Shimane, Japan. World Neurosurg 73:155-164, 2010

37. Isaksen J, Egge A, Waterloo K, Romner B, Ingebrigtsen T: Risk factors for aneurysmal subarachnoid haemorrhage: the Troms $\emptyset$ study. J Neurol Neurosurg Psychiatry 73:185-187, 2002

38. Juvela S, Porras M, Poussa K: Natural history of unruptured intracranial aneurysms: probability of and risk factors for aneurysm rupture. J Neurosurg 108:1052-1060, 2008

39. Juvela S, Poussa K, Porras M: Factors affecting formation and growth of intracranial aneurysms: a long-term follow-up study. Stroke 32:485-491, 2001

40. Kambam JR, Chen LH, Hyman SA: Effect of short-term smoking halt on carboxyhemoglobin levels and P50 values. Anesth Analg 65:1186-1188, 1986

41. Katsuta T, Inoue T, Arakawa S, Uda K: Cutaneous necrosis after superficial temporal artery-to-middle cerebral artery anastomosis: is it predictable or avoidable? Neurosurgery 49: 879-884, 2001

42. Khullar D, Maa J: The impact of smoking on surgical outcomes. J Am Coll Surg 215:418-426, 2012

43. Kim KT, Park SW, Kim YB: Disc height and segmental motion as risk factors for recurrent lumbar disc herniation. Spine (Phila Pa 1976) 34(24):2674-2678, 2009

44. Kleinman JC, Pierre MB Jr, Madans JH, Land GH, Schramm WF: The effects of maternal smoking on fetal and infant mortality. Am J Epidemiol 127:274-282, 1988

45. Koc K, Anik I, Bozkurt SU, Ercin C, Ceylan S: Effect of smoking on rat basilar artery: correlation with inducible nitric oxide synthase and endothelin converting enzyme-1. Turk Neurosurg 19:393-399, 2009

46. Koide M, Nishizawa S, Yamamoto S, Yamaguchi M, Namba $\mathrm{H}$, Terakawa S: Nicotine exposure, mimicked smoking, directly and indirectly enhanced protein kinase $\mathrm{C}$ activity in isolated canine basilar artery, resulting in enhancement of arterial contraction. J Cereb Blood Flow Metab 25:292-301, 2005

47. Koskenvuo K, Broms U, Korhonen T, Laitinen LA, HuunanSeppälä A, Keistinen T, et al: Smoking strongly predicts disability retirement due to COPD: the Finnish Twin Cohort Study. Eur Respir J 37:26-31, 2011

48. Krishnamurthy S, Kelleher JP, Lehman EB, Cockroft KM: Effects of tobacco dose and length of exposure on delayed neurological deterioration and overall clinical outcome after aneurysmal subarachnoid hemorrhage. Neurosurgery 61: 475-481, 2007

49. Kroll SS: Necrosis of abdominoplasty and other secondary flaps after TRAM flap breast reconstruction. Plast Reconstr Surg 94:637-643, 1994

50. Krueger JK, Rohrich RJ: Clearing the smoke: the scientific rationale for tobacco abstention with plastic surgery. Plast Reconstr Surg 108:1063-1077, 2001

51. Kuri M, Nakagawa M, Tanaka H, Hasuo S, Kishi Y: Determination of the duration of preoperative smoking cessation to improve wound healing after head and neck surgery. Anesthesiology 102:892-896, 2005

52. Lal BK, Beach KW, Roubin GS, Lutsep HL, Moore WS, Malas MB, et al: Restenosis after carotid artery stenting and endarterectomy: a secondary analysis of CREST, a randomised controlled trial. Lancet Neurol 11:755-763, 2012

53. Lau D, Ziewacz JE, Siddiqi HK, Pelly A, Sullivan SE, ElSayed AM: Cigarette smoking: a risk factor for postoperative morbidity and 1-year mortality following craniotomy for tumor resection. Clinical article. J Neurosurg 116:1204-1214, 2012

54. Lawson MF, Velat GJ, Fargen KM, Mocco J, Hoh BL: Interventional neurovascular disease: avoidance and management of complications and review of the current literature. J Neurosurg Sci 55:233-242, 2011

55. Lee TC, Ueng SW, Chen HH, Lu K, Huang HY, Liliang PC, et al: The effect of acute smoking on spinal fusion: an experimental study among rabbits. J Trauma 59:402-408, 2005

56. Lensmar C, Elmberger G, Sköld M, Eklund A: Smoking alters the phenotype of macrophages in induced sputum. Respir Med 92:415-420, 1998

57. Lindekleiv H, Sandvei MS, Njølstad I, Løchen ML, Romundstad PR, Vatten L, et al: Sex differences in risk factors for aneurysmal subarachnoid hemorrhage: a cohort study. Neurology 76:637-643, 2011

58. Lindström D, Sadr Azodi O, Wladis A, Tønnesen H, Linder $\mathrm{S}$, Nåsell $\mathrm{H}$, et al: Effects of a perioperative smoking cessation intervention on postoperative complications: a randomized trial. Ann Surg 248:739-745, 2008

59. Litvack ZN, West GA, Delashaw JB, Burchiel KJ, Anderson VC: Dural augmentation: part I-evaluation of collagen matrix allografts for dural defect after craniotomy. Neurosurgery 65:890-897, 2009

60. Lyons B, Frizelle H, Kirby F, Casey W: The effect of passive smoking on the incidence of airway complications in children undergoing general anaesthesia. Anaesthesia 51:324-326, 1996

61. Martin GJ Jr, Haid RW Jr, MacMillan M, Rodts GE Jr, Berkman R: Anterior cervical discectomy with freeze-dried fibula allograft. Overview of 317 cases and literature review. Spine (Phila Pa 1976) 24:852-859, 1999

62. Martínez-García E, Irigoyen M, González-Moreno O, Corrales L, Teijeira A, Salvo E, et al: Repetitive nicotine exposure leads to a more malignant and metastasis-prone phenotype of SCLC: a molecular insight into the importance of quitting smoking during treatment. Toxicol Sci 116:467-476, 2010

63. Mason DP, Subramanian S, Nowicki ER, Grab JD, Murthy SC, Rice TW, et al: Impact of smoking cessation before resection of lung cancer: a Society of Thoracic Surgeons General Thoracic Surgery Database study. Ann Thorac Surg 88: 362-371, 2009

64. Møller AM, Villebro N, Pedersen T, Tønnesen H: Effect of preoperative smoking intervention on postoperative complications: a randomised clinical trial. Lancet 359:114-117, 2002

65. Monfrecola G, Riccio G, Savarese C, Posteraro G, Procaccini EM: The acute effect of smoking on cutaneous microcirculation blood flow in habitual smokers and nonsmokers. Dermatology 197:115-118, 1998

66. Morris KM, Shaw MD, Foy PM: Smoking and subarachnoid haemorrhage: a case control study. Br J Neurosurg 6:429432, 1992

67. Myers K, Hajek P, Hinds C, McRobbie H: Stopping smoking shortly before surgery and postoperative complications: a systematic review and meta-analysis. Arch Intern Med 171: 983-989, 2011

68. Nåsell H, Adami J, Samnegård E, Tønnesen H, Ponzer S: Effect of smoking cessation intervention on results of acute fracture surgery: a randomized controlled trial. J Bone Joint Surg Am 92:1335-1342, 2010

69. Nassiri N, Cleary DR, Ueeck BA: Is cranial reconstruction with a hard-tissue replacement patient-matched implant as safe as previously reported? A 3-year experience and review of the literature. J Oral Maxillofac Surg 67:323-327, 2009

70. O'Rourke JM, Kalish LA, McDaniel S, Lyons B: The effects of exposure to environmental tobacco smoke on pulmonary function in children undergoing anesthesia for minor surgery. Paediatr Anaesth 16:560-567, 2006 
71. Pearce AC, Jones RM: Smoking and anesthesia: preoperative abstinence and perioperative morbidity. Anesthesiology 61:576-584, 1984

72. Peolsson A, Vavruch L, Oberg B: Predictive factors for arm pain, neck pain, neck specific disability and health after anterior cervical decompression and fusion. Acta Neurochir (Wien) 148:167-173, 2006

73. Pleis JR, Lucas JW, Ward BW: Summary Health Statistics for U.S. Adults: National Health Interview Survey, 2008. National Center for Health Statistics, 2009 (http://www.cdc. gov/nchs/data/series/sr_10/sr10_242.pdf) [Accessed May 14, 2013]

74. Pobereskin LH: Influence of premorbid factors on survival following subarachnoid hemorrhage. J Neurosurg 95:555559,2001

75. Qureshi AI, Sung GY, Suri MF, Straw RN, Guterman LR, Hopkins LN: Factors associated with aneurysm size in patients with subarachnoid hemorrhage: effect of smoking and aneurysm location. Neurosurgery 46:44-50, 2000

76. Qureshi AI, Suri MF, Yahia AM, Suarez JI, Guterman LR, Hopkins LN, et al: Risk factors for subarachnoid hemorrhage. Neurosurgery 49:607-613, 2001

77. Rahme RJ, Batjer HH, Bendok BR: Multiplicative impact of smoking and genetic predisposition on intracranial aneurysm formation. Neurosurgery 67:N15-N16, 2010

78. Rees TD, Liverett DM, Guy CL: The effect of cigarette smoking on skin-flap survival in the face lift patient. Plast Reconstr Surg 73:911-915, 1984

79. Riefkohl R, Wolfe JA, Cox EB, McCarty KS Jr: Association between cutaneous occlusive vascular disease, cigarette smoking, and skin slough after rhytidectomy. Plast Reconstr Surg 77:592-595, 1986

80. Rigotti NA, McKool KM, Shiffman S: Predictors of smoking cessation after coronary artery bypass graft surgery. Results of a randomized trial with 5-year follow-up. Ann Intern Med 120:287-293, 1994

81. Rockman CB, Cappadona C, Riles TS, Lamparello PJ, Giangola G, Adelman MA, et al: Causes of the increased stroke rate after carotid endarterectomy in patients with previous strokes. Ann Vasc Surg 11:28-34, 1997

82. Saetta MTG, Turato G, Baraldo S, Zanin A, Braccioni F, Mapp CE, et al: Goblet cell hyperplasia and epithelial inflammation in peripheral airways of smokers with both symptoms of chronic bronchitis and chronic airflow limitation. Am J Respir Crit Care Med 161:1016-1021, 2000

83. Sandén BFP, Försth P, Michaëlsson K: Smokers show less improvement than nonsmokers two years after surgery for lumbar spinal stenosis: a study of 4555 patients from the Swedish spine register. Spine (Phila Pa 1976) 36:1059-1064, 2011

84. Sarin CL, Austin JC, Nickel WO: Effects of smoking on digital blood-flow velocity. JAMA 229:1327-1328, 1974

85. Sasco AJ, Secretan MB, Straif K: Tobacco smoking and cancer: a brief review of recent epidemiological evidence. Lung Cancer 45 Suppl 2:S3-S9, 2004

86. Schroeder SA: Tobacco control in the wake of the 1998 master settlement agreement. N Engl J Med 350:293-301, 2004

87. Schwab FJ, Nazarian DG, Mahmud F, Michelsen CB: Effects of spinal instrumentation on fusion of the lumbosacral spine. Spine (Phila Pa 1976) 20:2023-2028, 1995

88. Shi Y, Warner DO: Pediatric surgery and parental smoking behavior. Anesthesiology 115:12-17, 2011

89. Singh JAHT, Houston TK, Ponce BA, Maddox G, Bishop MJ, Richman J, et al: Smoking as a risk factor for short-term outcomes following primary total hip and total knee replacement in veterans. Arthritis Care Res (Hoboken) 63:1365-1374, 2011

90. Sørensen LT: Wound healing and infection in surgery. The clinical impact of smoking and smoking cessation: a systematic review and meta-analysis. Arch Surg 147:373-383, 2012
91. Sørensen LT, Jørgensen T: Short-term pre-operative smoking cessation intervention does not affect postoperative complications in colorectal surgery: a randomized clinical trial. Colorectal Dis 5:347-352, 2003

92. Swartz KR, Trost GR: Recurrent lumbar disc herniation. Neurosurg Focus 15(3):E10, 2003

93. Theadom A, Cropley M: Effects of preoperative smoking cessation on the incidence and risk of intraoperative and postoperative complications in adult smokers: a systematic review. Tob Control 15:352-358, 2006

94. Thomsen T, Villebro N, Møller AM: Interventions for preoperative smoking cessation. Cochrane Database Syst Rev (7): CD002294, 2010

95. Tur E, Yosipovitch G, Oren-Vulfs S: Chronic and acute effects of cigarette smoking on skin blood flow. Angiology 43: 328-335, 1992

96. Turan A, Mascha EJ, Roberman D, Turner PL, You J, Kurz A, et al: Smoking and perioperative outcomes. Anesthesiology 114:837-846, 2011

97. Underwood MJ, Bailey JS: Coronary bypass surgery should not be offered to smokers. BMJ 306:1047-1048, 1993

98. Wang WH, Wang DX: Role of sympathetic nerve and adrenal gland in the potentiation of hypoxic pulmonary vasoconstriction during cigarette smoking. J Tongji Med Univ 12: $1-5,1992$

99. Warner DO: Helping surgical patients quit smoking: why, when, and how. Anesth Analg 101:481-487, 2005

100. Warner DO: Perioperative abstinence from cigarettes: physiologic and clinical consequences. Anesthesiology 104:356367,2006

101. Warner DO: Preoperative smoking cessation: the role of the primary care provider. Mayo Clin Proc 80:252-258, 2005

102. Warner DO: Tobacco dependence in surgical patients. Curr Opin Anaesthesiol 20:279-283, 2007

103. Warner DO, Klesges RC, Dale LC, Offord KP, Schroeder DR, Vickers KS, et al: Telephone quitlines to help surgical patients quit smoking patient and provider attitudes. Am J Prev Med 35 (6 Suppl):S486-S493, 2008

104. Warner DO, Sarr MG, Offord KP, Dale LC: Anesthesiologists, general surgeons, and tobacco interventions in the perioperative period. Anesth Analg 99:1766-1773, 2004

105. Webster RC, Kazda G, Hamdan US, Fuleihan NS, Smith $\mathrm{RC}$ : Cigarette smoking and face lift: conservative versus wide undermining. Plast Reconstr Surg 77:596-604, 1986

106. Weir BK, Kongable GL, Kassell NF, Schultz JR, Truskowski LL, Sigrest A: Cigarette smoking as a cause of aneurysmal subarachnoid hemorrhage and risk for vasospasm: a report of the Cooperative Aneurysm Study. J Neurosurg 89:405-411, 1998

107. Wong LS, Martins-Green M: Firsthand cigarette smoke alters fibroblast migration and survival: implications for impaired healing. Wound Repair Regen 12:471-484, 2004

108. Zdeblick TA: A prospective, randomized study of lumbar fusion. Preliminary results. Spine (Phila Pa 1976) 18:983991, 1993

109. Zhang Q, Tang X, Zhang ZF, Velikina R, Shi S, Le AD: Nicotine induces hypoxia-inducible factor-1alpha expression in human lung cancer cells via nicotinic acetylcholine receptor-mediated signaling pathways. Clin Cancer Res 13: 4686-4694, 2007

Manuscript submitted November 30, 2012.

Accepted May 9, 2013.

Please include this information when citing this paper: published online June 18, 2013; DOI: 10.3171/2013.5.JNS122287.

Address correspondence to: John Maa, M.D., 521 Parnassus Ave., C 341, San Francisco, CA 94131-0790. email: john.maa@ ucsfmedctr.org. 